\title{
The different pathogenesis of sporadic adenoma and adenocarcinoma in non-ampullary lesions of the proximal and distal duodenum
}

\author{
Ayumi Niwa ${ }^{1, *}$, Seiya Kuwano ${ }^{1, *}$, Hiroyuki Tomita ${ }^{1}$, Keita Kimura ${ }^{1}$, Yukiya Orihara ${ }^{1}$, \\ Tomohiro Kanayama ${ }^{1}$, Kei Noguchi ${ }^{1}$, Kenji Hisamatsu ${ }^{1}$, Takayuki Nakashima ${ }^{1}$, \\ Yuichiro Hatano${ }^{1}$, Akihiro Hirata², Tatsuhiko Miyazaki³, Kazuhiro Kaneko4, Takuji \\ Tanaka $^{5}$ and Akira Hara ${ }^{1}$ \\ ${ }^{1}$ Department of Tumor Pathology, Gifu University Graduate School of Medicine, Gifu, Japan \\ ${ }^{2}$ Division of Animal Experiment, Life Science Research Center, Gifu University, Gifu, Japan \\ ${ }^{3}$ Division of Pathology, Gifu University Hospital, Gifu, Japan \\ ${ }^{4}$ Department of Gastroenterology, Endoscopy Division, National Cancer Center Hospital East, Kashiwa, Japan \\ ${ }^{5}$ Department of Diagnostic Pathology (DDP) and Research Center of Diagnostic Pathology (RC-DiP), Gifu Municipal Hospital, \\ Gifu, Japan \\ *These authors have contributed equally to this work \\ Correspondence to: Hiroyuki Tomita, email: h_tomita@gifu-u.ac.jp \\ Keywords: duodenal neoplasms, beta-catenin \\ Received: October 24, $2016 \quad$ Accepted: February 27, $2017 \quad$ Published: April 12, 2017 \\ Copyright: Niwa et al. This is an open-access article distributed under the terms of the Creative Commons Attribution License 3.0 \\ (CC BY 3.0), which permits unrestricted use, distribution, and reproduction in any medium, provided the original author and source \\ are credited.
}

\section{ABSTRACT}

Non-ampullary duodenal adenoma with activation of Wnt/ $\beta$-catenin signalling is common in familial adenomatous polyposis (FAP) patients, whereas sporadic nonampullary adenoma is uncommon. The adenoma-carcinoma sequence similar to colon cancer is associated with duodenal tumors in FAP, but not always in sporadic tumors. We obtained 37 non-ampullary duodenal tumors, including 25 adenomas and 12 adenocarcinomas, were obtained from biopsies and endoscopic resections. We performed immunohistochemistry for $\beta$-catenin, the hallmark of Wnt activation, and aldehyde dehydrogenase 1 (ALDH1), a putative cancer stem cell marker. In non-ampullary lesions, abnormal nuclear localization of $\beta$-catenin was observed in $21(84.0 \%)$ of 25 adenomas and $4(33.3 \%)$ of 12 adenocarcinomas. In the proximal duodenum, nuclear $\beta$-catenin was less frequent in both adenomas and adenocarcinomas. Gastric duodenal metaplasia (GDM) was observed only in the proximal duodenum. All adenomas with GDM were the gastric foveolar and pyloric gland types, and showed only membranous $\beta$-catenin. The intestinal-type adenomas had nuclear $\beta$-catenin in the proximal and distal duodenum. ALDH1-positive cells were more frequent in adenocarcinomas than adenomas. Nuclear $\beta$-catenin accumulation frequently occurred in ALDH1-positive cells in adenoma, but not in adenocarcinoma. In the non-ampullary proximal duodenum, $\mathbf{W n t} / \beta$-catenin pathway activation was more closely associated with adenomas than adenocarcinomas, and while it might cooperate with ALDH1 in adenoma, it does not in adenocarcinoma. The pathogenesis thus may differ between sporadic adenoma and adenocarcinoma of nonampullary duodenal lesions, especially in the proximal and distal duodenum.

\section{INTRODUCTION}

Most small intestine adenomas, including the ampulla of Vater, develop in the duodenum. Among these, sporadic non-ampullary (except the ampulla of Vater) duodenal adenomas are uncommon $[1,2]$ compared to adenomas in familial adenomatous polyposis (FAP), with a germline mutation in the adenomatous polyposis coli 
$(A P C)$ gene. Approximately $60 \%$ of duodenal adenomas develop in patients with FAP, while the remaining $40 \%$ are sporadic [3]. Non-ampullary duodenal adenoma is thought to be a precancerous lesion, and the model of the adenoma-carcinoma sequence is predicted to involve the small intestine, including the duodenum and colorectum [4-6].

The Wnt/ $\beta$-catenin pathway promotes organ development and tissue homeostasis [7], and disruption of the pathway causes various malignancies [8]. $\beta$-catenin, which binds to the product of the $A P C$ gene, is a multifunctional cytoplasmic protein with a molecular weight of $92 \mathrm{kDa}$ [9]. The accumulation of $\beta$-catenin in the nucleus is the hallmark of Wnt pathway activation, and leads to cell proliferation by activating lymphoid enhancer factor/T-cell factor transcription factors [7]. Wnt pathway activation, particularly by $A P C$ and $C T N N B 1$ gene mutation, is associated with early events in colon carcinogenesis in the model of the adenomacarcinoma sequence [9]. Nuclear $\beta$-catenin translocation increased with the progression of colorectal tissue from normal epithelial tissue, adenomas, to carcinomas in the colorectum [10].

The aldehyde dehydrogenase (ALDH) superfamily constitutes a group of $\mathrm{NAD}(\mathrm{P})^{+}$-dependent enzymes that metabolize endogenous and exogenous aliphatic and aromatic aldehyde molecules by oxidation to their corresponding carboxylic acids [13]. The human genome includes 19 known $A L D H$ genes [14]. ALDH1 is a cytoplasmic member of the ALDH family of enzymes. ALDH1 expression was originally detected in a small subpopulation of hematopoietic stem/progenitor cells [15, 16]. ALDH1 is thought to be a putative cancer stem cell marker in the stomach and colorectal cancers $[17,18]$.

In the majority of colorectal cancers, the $\mathrm{Wnt} / \beta$ catenin pathway is necessary for the self-renewal of cancer stem cells (CSCs) $[19,20]$. On the other hand, ALDH1 is a putative CSC marker, and ALDH1-positive cells have CSC potential in colorectal and gastric cancers [17, 2123]. ALDH1-positive cells have shown higher levels of the regulatory components of $\mathrm{Wnt} / \beta$-catenin signalling, such as $\beta$-catenin and TCF-4, compared with ALDH1-negative cells in breast cancer [24].

Gastric duodenal metaplasia (GDM) is a histologically detectable mucosal change thought to evolve following Helicobacter pylori infection, celiac disease, or Crohn's disease [25-27]. The regenerative stimuli are caused by an aberrant high production of gastric acid triggered by Helicobacter pylori infection [28]. GDM has been found even in the absence of these conditions and in duodenal adenomas [29]. Non-ampullary adenoma/carcinoma more often develops on the oral (proximal) side of the ampulla in Japan because of the higher rate of $H$. pylori infection compared with that in Western countries [30]. Further, the anal (distal) side of non-ampullary adenoma/carcinoma frequently occurs with colon adenoma/carcinoma, which may be influenced by bile acids [30].

In this study, we evaluated $\beta$-catenin and ALDH1 expression in non-ampullary duodenal adenomas and adenocarcinomas using immunohistochemistry (IHC), and investigated the clinicopathological characteristics and non-ampullary duodenal carcinogenesis to provide a foundation for therapy development.

\section{RESULTS}

\section{Case pathology}

Thirty-seven patients were included in this study (Table 1), 29 of which were male and 8 were female. A total of 25 sporadic non-ampullary duodenal adenomas (25 patients) and 12 sporadic non-ampullary duodenal adenocarcinomas ( 9 patients) were obtained during the study period. Patient ages ranged from 26 to 77 years (mean, 40.5 years). The tumor position in the duodenum, except the ampulla of Vater, was separated into two parts. The upper part (proximal) was from the bulb to the periampulla, while the lower part (distal) was from the periampulla to the descending duodenum. Most adenocarcinomas were detected in the upper part ( 9 of 12 cases) because all adenocarcinoma cases were resected using the limiting technique, i.e. EMR/ESD. Biopsy was performed on 16 lesions (43.2\%) and EMR/ESD was performed on 21 lesions (56.8\%). Tumor size ranged from 4 to $70 \mathrm{~mm}$ (mean, $37.0 \mathrm{~mm}$ ), and the tumor size of adenocarcinoma patients was higher than that of adenoma patients $(P<0.05)$. Additionally, no patients had a family history of Lynch syndrome.

\section{Nuclear $\beta$-catenin expression was frequent in adenoma but not adenocarcinoma in the non- ampullary duodenum}

To investigate the expression of $\beta$-catenin in nonampullary duodenal adenoma and adenocarcinoma, we performed IHC with a $\beta$-catenin antibody. Normal epithelium in the duodenum showed strong membranous staining for $\beta$-catenin with a few nuclear $\beta$-cateninpositive cell in the bottom, and aberrant expression was observed in both adenoma and adenocarcinoma (Figure $1 \mathrm{~A}$ and Supplementary Figure 1). Abnormal nuclear localization of $\beta$-catenin was observed in $21(86.4 \%)$ of 25 adenomas, which was higher than the $4(22.2 \%)$ observed in 12 adenocarcinomas (Figure 1B). These data suggest that $\mathrm{Wnt} / \beta$-catenin activation is more closely associated with adenoma compared with adenocarcinoma in nonampullary lesions.

Non-ampullary duodenal adenomas with high-grade dysplasia and large size ( $\geq 20 \mathrm{~mm}$ in diameter) indicate a high risk of progression to adenocarcinoma [31]. In our cohort, $14(56 \%)$ of 25 adenomas were more than 
Table 1: Patient characteristics

\begin{tabular}{lccc}
\hline Characteristic & Adenoma, $\mathbf{n}(\%)$ & Carcinoma, $\mathbf{n}(\mathbf{\%})$ & Total, $\mathbf{n}(\mathbf{\%})$ \\
\hline Total no. of patients & $25(67.6)$ & $12(22.4)$ & $37(100)$ \\
Age, yr & $62.4 \pm 13.4(26-75)$ & $70.2 \pm 7.4(61-77)$ & $66.3 \pm 4.3(26-77)$ \\
Sex & & & \\
$\quad$ Female & $6(75)$ & $2(25)$ & $29(100)$ \\
$\quad$ Male & $20(58.1)$ & $9(25.8)$ & $37(100)$ \\
Total no. of lesions & $25(67.6)$ & $12(29.4 \%)$ & $16(100)$ \\
Method & $16(100)$ & $0(0)$ & $21(100)$ \\
$\quad \begin{array}{l}\text { Biopsy } \\
\text { EMR or ESD }\end{array}$ & $10(47.6)$ & $11(52.4)$ & $25(100)$ \\
$\begin{array}{l}\text { Tumor position in duodenum } \\
\text { Upper part (Bulb to } \\
\text { periampulla) } \\
\begin{array}{l}\text { Lower part (Periampulla } \\
\text { to descending) }\end{array}\end{array}$ & $16(64)$ & $9(36)$ & $12(100)$ \\
$\begin{array}{l}\text { Tumor size (largest } \\
\text { diameter, mm) }\end{array}$ & $9(75)$ & $3(25)$ & $23.7 \pm 5.4(4-70)$ \\
\hline
\end{tabular}

Data are presented as average $\pm \mathrm{SD}$ (mean range).

EMR, endoscopic mucosal resection; ESD, endoscopic submucosal dissection.

${ }^{*} P<0.05$ : adenoma versus adenocarcnoma in the tumor size

$20 \mathrm{~mm}$ at their largest diameter, and nuclear $\beta$-catenin was frequent $(93 \%)$ in these large adenomas $(\geq 20 \mathrm{~mm})$ (Table 2). These results indicate that $\mathrm{Wnt} / \beta$-catenin activation may contribute to the progression of sporadic non-ampullary duodenal adenoma similar to colorectal carcinogenesis. On the other hand, the relationship between nuclear $\beta$-catenin, i.e., Wnt activation, and tumor size may be associated with aberrant apoptosis of tumor cells. This may be supported by previous reports nuclear $\beta$-catenin contributes to increased tumor size [32, 33]. Nuclear $\beta$-catenin is less frequent in adenocarcinoma than in adenoma in non-ampullary lesions. This suggests the conventional adenoma-carcinoma sequence associated with activation of $\mathrm{Wnt} / \beta$-catenin pathway may be less frequent in non-ampullary lesions compared with colon carcinogenesis.

\section{GDM was observed only in gastric type adenoma with membranous $\beta$-catenin}

We focused on the positional differences and histological subtypes of adenomas and adenocarcinomas of non-ampullary duodenal lesions. In the initial manifestation of GDM of our cohort, small patches of gastric foveolar cells appear near the tip of a villus (Figure 2A). The patchy GDM in the duodenal mucosa indicates that GDM might be a reactive metaplasia rather than a congenital lesion. GDM was found in 4 (16\%) of 25 adenomas and all the cases were located in the proximal duodenum. It follows that GDM is commonly observed in the proximal duodenum and is associated with peptic ulceration caused by Helicobacter pylori infection in most cases [34].

To clarify what types of adenomas are associated with GDM, we performed IHC for CDX-2 (a marker of intestinal origin), MUC5AC (a marker of gastric foveolar mucin), and MUC6 (a marker of gastric pyloric gland mucin). All 4 cases with GDM were gastric type adenomas. Two foveolar-type adenomas showed CDX-2(-), MUC5AC(+), MUC6(-), and 2 pyloric gland adenomas showed CDX-2(-), MUC5AC(-), MUC6(+) (Figure 2B). GDM is frequently observed in gastric type adenoma and/ or heterotopic gastric mucosa in the duodenum [35], and $\beta$-catenin expression is almost only in the membrane, but not the nucleus [36].

All 4 of our cases showed only membranous $\beta$-catenin expression. The other 21 adenomasshowed nuclear $\beta$-catenin expression and these were all intestinaltype adenomas identified with expressions of CDX2(+), MUC5AC(-), and MUC6(-) (Table 2). These data suggest that activation of the $\mathrm{Wnt} / \beta$-catenin pathway is not involved in the development of gastric-type 
duodenal adenoma with GDM in non-ampullary lesions. Consequently, total 25 adenomas were divided into 4 gastric-type adenomas ( 2 foveolar-type adenomas and 2 pyloric gland adenomas) and 21 intestinal-type adenomas.

Next, we investigated the $\beta$-catenin expression pattern in different locations of adenomas and adenocarcinoma in the duodenum. We divided the part of non-ampullary duodenum; the upper (proximal) part from the bulb to the periampulla and the lower (distal) part from the periampulla to the descending duodenum. Nuclear $\beta$-catenin was frequent in adenoma and adenocarcinoma of the lower part and adenoma of the upper part (Figure 3). However, in the upper part, adenomas and adenocarcinomas with membranous $\beta$-catenin
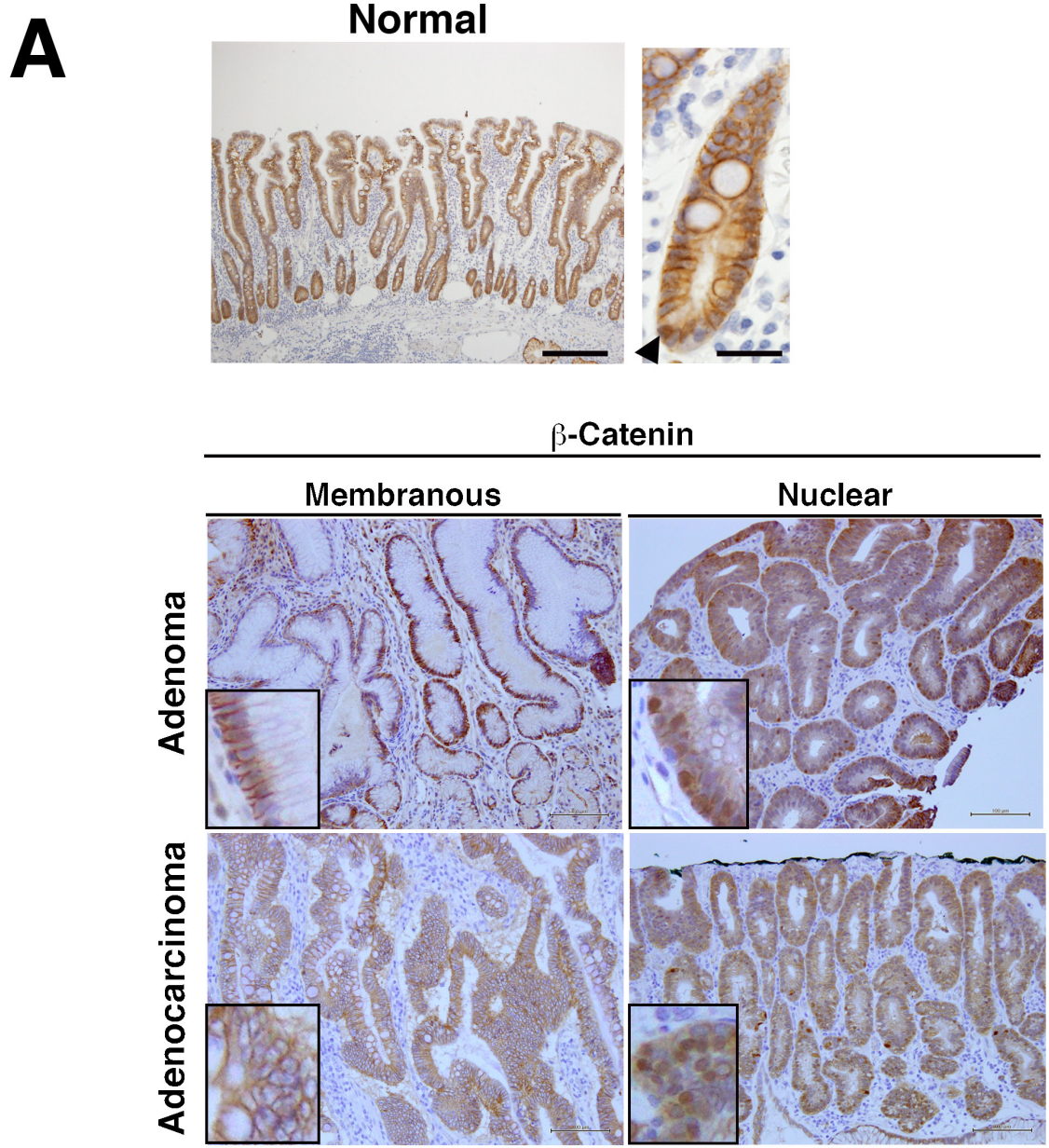

B

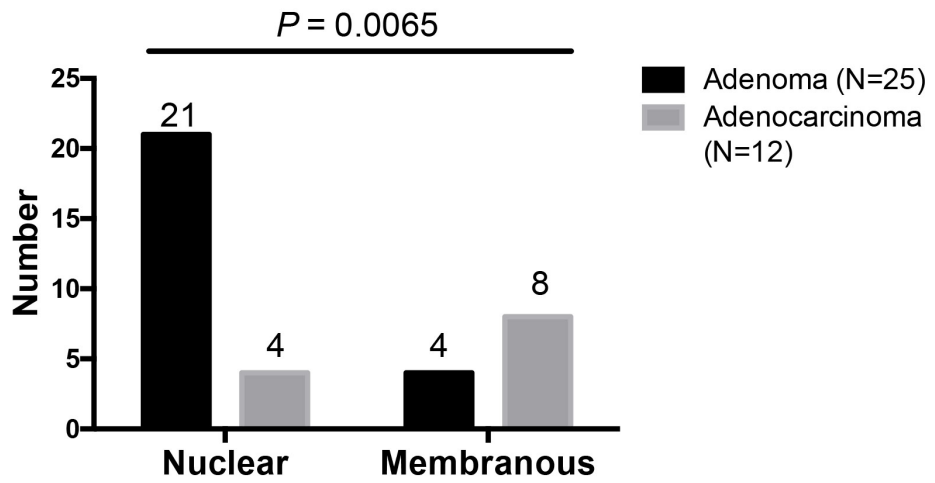

Figure 1: $\boldsymbol{\beta}$-Catenin expression in adenoma and adenocarcinoma of the non-ampullary duodenum. (A) Representative photos of membranous and nuclear $\beta$-catenin expression in normal mucosa, adenoma, and adenocarcinoma. The upper panel (left) indicates a normal epithelium with a nuclear $\beta$-catenin positive cell. Insets in adenomas and adenocarcinomas: enlarged photos at the high-power field in each photo. Bars: $100 \mu \mathrm{m}$. (B) Number of nuclear or membranous expression of $\beta$-catenin in adenomas and adenocarcinomas. 
Table 2: $\beta$-Catenin expression in non-ampullary adenoma $(n=25)$

\begin{tabular}{|c|c|c|c|c|}
\hline & \multicolumn{2}{|c|}{$\beta$-Catenin expression } & & \\
\hline & Nuclear/cytoplasmic & Membranous & & \\
\hline \multicolumn{5}{|c|}{$\begin{array}{l}\text { Tumor size (largest } \\
\text { diameter, } \mathrm{mm} \text { ) }\end{array}$} \\
\hline$\geq 20 \mathrm{~mm}$ & $13(13 \%)$ & $1(7 \%)$ & $14(56 \%)$ & \\
\hline$<20 \mathrm{~mm}$ & $3(27 \%)$ & $8(73 \%)$ & $11(44 \%)$ & $P=0.0021^{\mathrm{a}}$ \\
\hline GDM $(+)$ & 0 & $4(16 \%)$ & $4(16 \%)$ & \\
\hline GDM (-) & $21(84 \%)$ & 0 & $21(84 \%)$ & $P<0.001^{\mathrm{a}}$ \\
\hline
\end{tabular}

GDM, Gastroduodenal metaplasia

a) Nuclear/cytoplasmic versus membranous staining in $\beta$-catenin
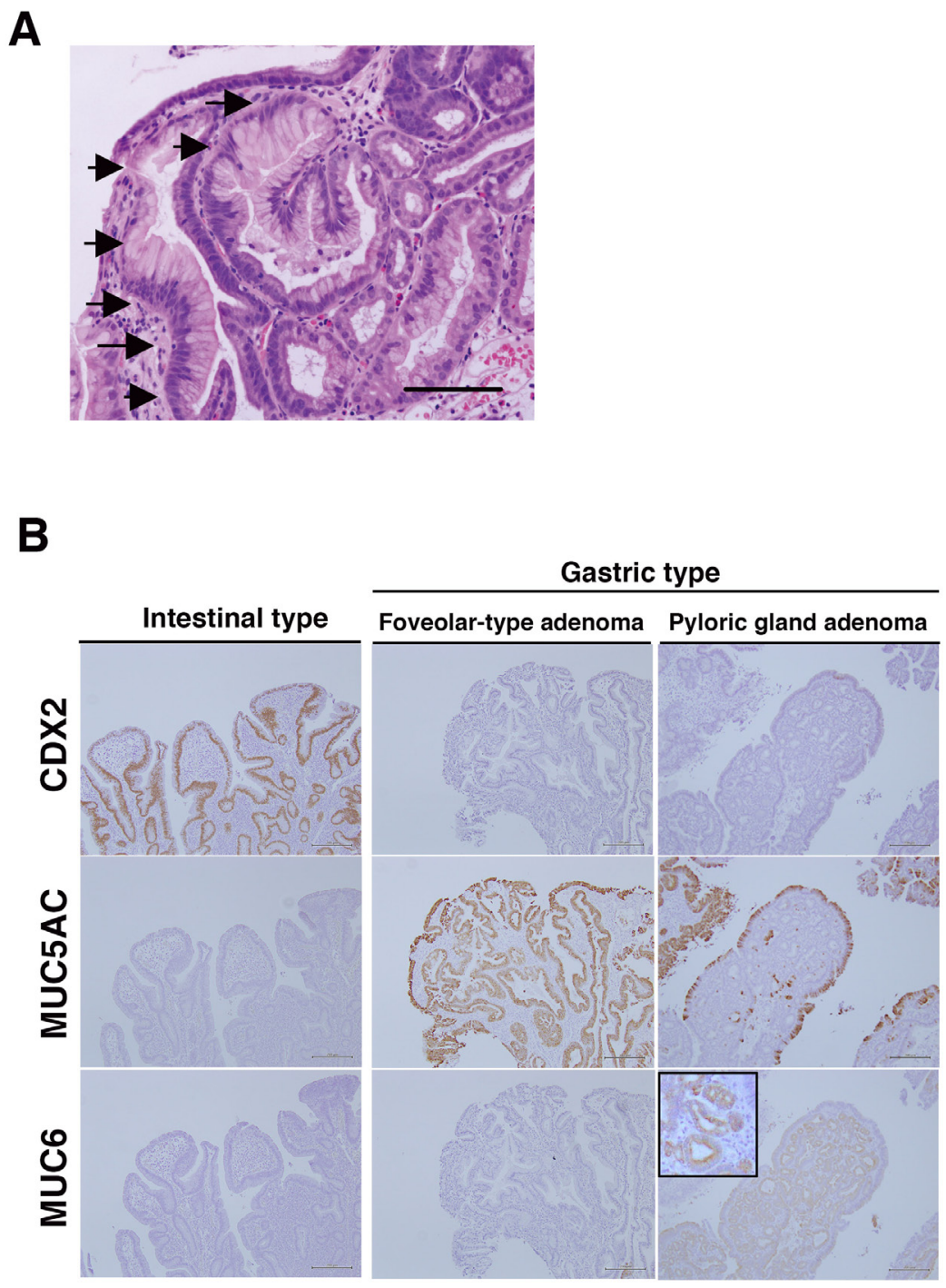

Figure 2: Gastric duodenal metaplasia (GDM) and histological types of duodenal adenomas in non-ampullary lesions. (A) Representative GDM in the superficial epithelium of non-ampullary adenoma. Arrows indicate the gastric foveolar epithelium-like lesions with GDM. Bars: $200 \mu \mathrm{m}$. (B) CDX2, MUC5AC, and MUC6 expressions in intestinal-type and gastric type, i.e., foveolar-type, pyloric gland, adenoma. Inset: enlarged photo at the high-power field. Bars: $200 \mu \mathrm{m}$. 
accounted for 4 (25\%) of 16 adenomas and $6(66.7 \%)$ of 9 adenocarcinomas, respectively; this difference was statistically significant. Our data indicates that a subset of sporadic adenocarcinomas in the proximal duodenum might be independent of the $\mathrm{Wnt} / \beta$-catenin pathway, while a subset of adenocarcinomas in the proximal duodenum is associated with the $\mathrm{Wnt} / \beta$-catenin pathway as well as the distal duodenum.

\section{ALDH1-positive cells showed significantly increased adenocarcinoma compared with adenoma}

We investigated ALDH1 expression in nonampullary duodenal adenoma and adenocarcinoma by IHC analysis. ALDH-positive cells were not detected in normal duodenal epithelium; however, ALDH1-positive cells were observed in adenomas and adenocarcinomas (Figure 4A). ALDH1 protein showed predominantly cytoplasmic expression in the tumor cell. Further, we analysed the signal intensity scores of ALDH1 immunostaining in adenoma and adenocarcinoma. The signal intensity was significantly higher in adenocarcinomas than adenomas (Figure 4B), indicating that ALDH1 may associated with the progression from adenoma to adenocarcinoma in nonampullary lesions.

\section{ALDH1-positive tumour cells were frequently co-localized with nuclear $\beta$-catenin in adenoma}

To investigate whether Wnt/ $\beta$-catenin and ALDH1 activation occur in the same tumor cells of adenoma and adenocarcinoma, we performed both IF and IHC staining for distinct conclusion. In the IF assay, the co-localization of nuclear $\beta$-catenin and ALDH1 strong expression was observed in tumor cells of adenoma and adenocarcinoma (Figure 5A). In the IHC assay, we could more clearly detect the co-expressed cells. To evaluate the number

\section{Upper part of non-ampullary duodenum}

(Bulb to periampulla lesion)

$\begin{array}{ccc} & \multicolumn{2}{c}{\beta \text {-Catenin expression }} \\$\cline { 2 - 3 } & \text {$\left.Nuclear } & \text { Membranous } \\ \text { Adenoma } & 12 & 4 \\ \text { Adenocarcinoma } & 3 & 6\end{array}\right] P=0.03$

Lower part of non-ampullary duodenum (Periampulla to discending lesion)

\begin{tabular}{ccc} 
& \multicolumn{2}{c}{$\beta$-Catenin expression } \\
\cline { 2 - 3 } & Nuclear & Membranous \\
\hline Adenoma & 9 & 0 \\
Adenocarcinoma & 2 & 1 \\
\hline Total & 11 & 1
\end{tabular}

Figure 3: $\beta$-Catenin expression and tumor position in non-ampullary adenomas and adenocarcinomas. Numbers of nuclear or membranous $\beta$-catenin expression in adenomas and adenocarcinomas in "Upper part" and "Lower part" of non-ampullary duodenum except the ampulla of Vater. 
of nuclear $\beta$-catenin- and/or ALDH1-positive cells, we calculated the number of only ALDH1-positive, only $\beta$-catenin-positive, or double positive cells in all the tumor cells of independent 5 fields. The percentage of nuclear $\beta$-catenin- and ALDH1-positive cells in tumor cells were predominantly co-expressed in adenoma compared with adenocarcinomas (Figure 5B). In adenomas, only ALDH1-positive cells, only nuclear $\beta$-catenin-positive cells, and double-positive cells of nuclear $\beta$-catenin and ALDH1 were $4.83 \%, 2.15 \%$, and $4.14 \%$, respectively, in the region in which nuclear $\beta$-catenin was observed most frequently. Inadenocarcinomas, only ALDH1-positive cells, only nuclear $\beta$-catenin-positive cells, and double positive cells were $11.5 \%, 0.06 \%$, and $0.41 \%$, respectively. Further, the positivity of nuclear $\beta$-catenin-positive cells in total ALDH1-posive cells between adenomas and adenocarcinomas, resulting that the positivity in adenomas was much more than in adenocarcinomas (Figure 5B). These data suggest that Wnt/ $\beta$-catenin signalling pathway might be associated with CSCs marked by ALDH1 in adenoma rather than adenocarcinoma.

\section{DISCUSSION}

In this study, we clarified the expression of $\beta$-catenin and ALDH1 in sporadic adenomas and adenocarcinomas in non-ampullary duodenal lesions by IHC. We have suggested the pathogenesis in sporadic non-ampullary duodenal adenoma and adenocarcinoma(Figure 6). We demonstrated that the $\mathrm{Wnt} / \beta$-catenin pathway was associated with intestinal type adenoma in the proximal and distal duodenum, while the pathway was independent

\section{A}
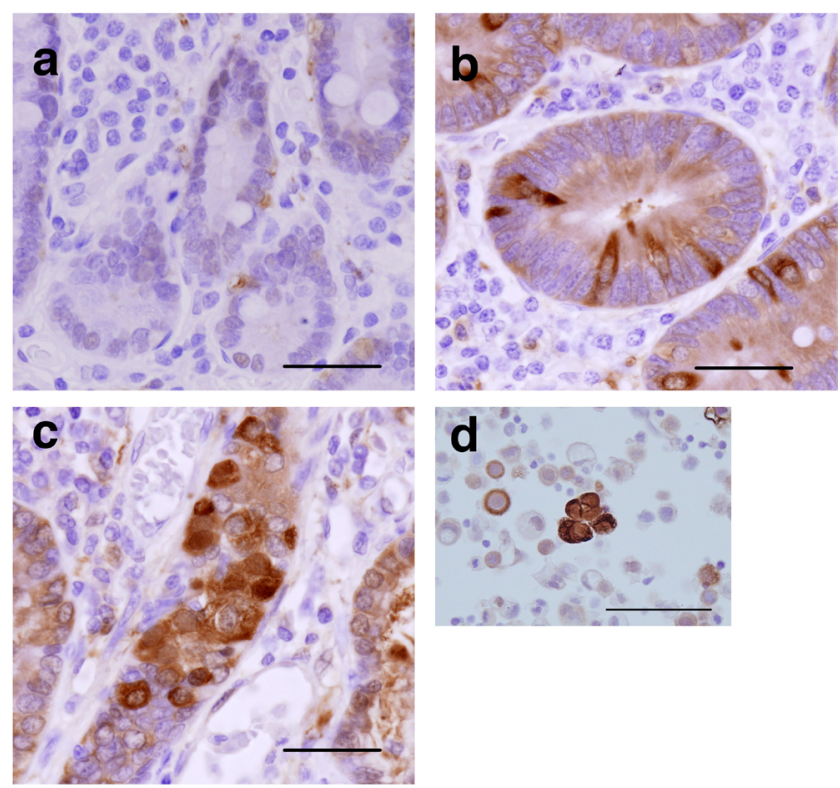

B

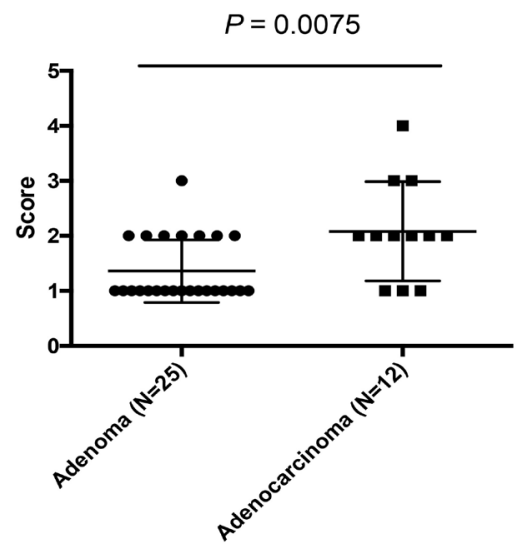

Figure 4: ALDH1 expression as assessed by IHC in non-ampullary duodenal adenomas and adenocarcinomas. (A) Representative photos of non-ampullary duodenal lesions. (a) Normal epithelium. (b) Adenoma. (c) Adenocarcinoma. Bars: $100 \mu \mathrm{m}$ (d) Lung cancer cells as a positive control of ALDH1 staining (Roudi R, Cancer Invest. 2015). Bar: 50 $\mu$ m. (B) Data for ALDH1 expression scores (1 to 4) in adenomas and adenocarcinomas. (See also Materials and Methods). 
A (a)

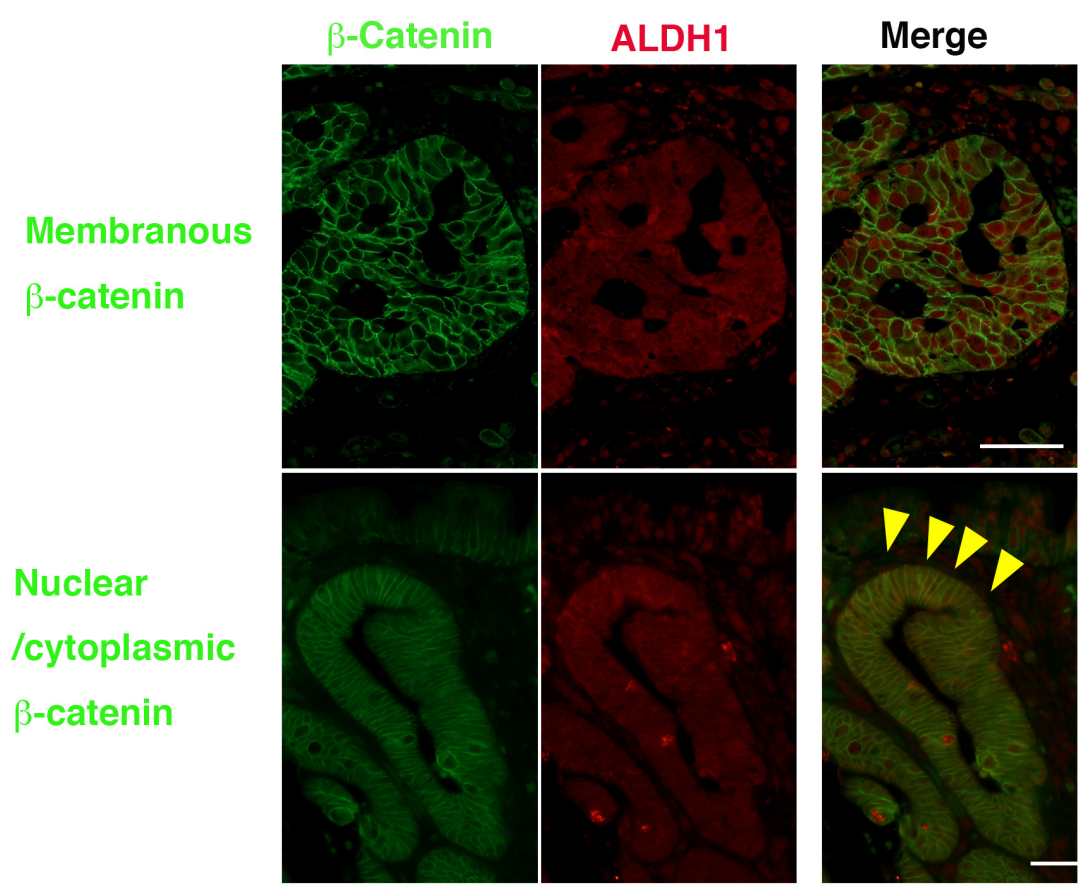

(b)

Blue: $\beta$-Catenin

Brown:ALDH1

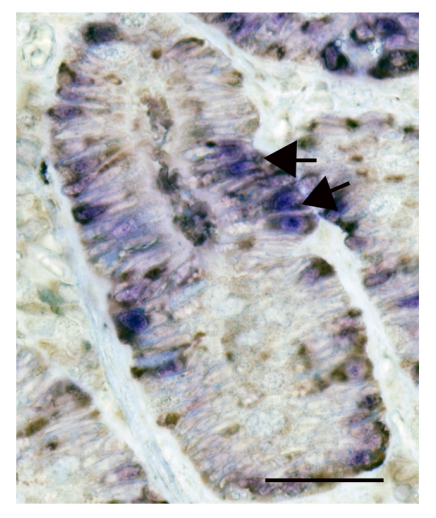

B (a)

(\%)

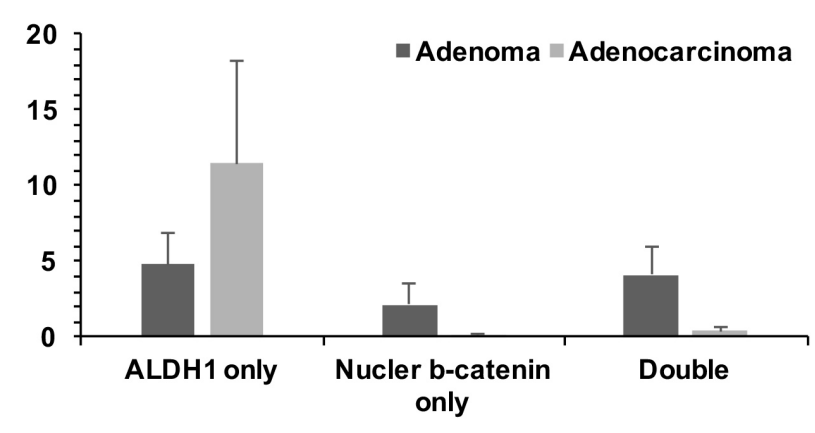

(b)

\section{(\%)}

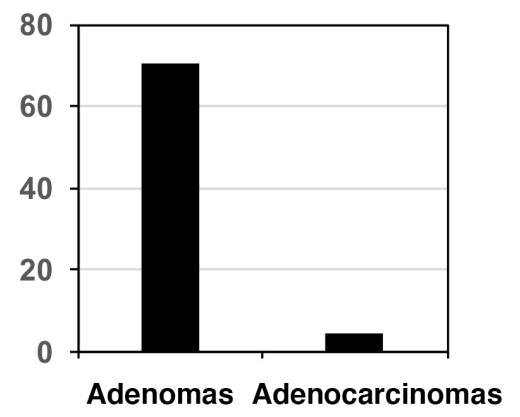

Figure 5: The co-expression of $\beta$-catenin and ALDH1 in non-ampullary adenomas and adenocarcinomas. (A) (a) Double immunofluorescent staining of $\beta$-catenin (green) and ALDH1 (red) in representative adenomatous lesions (adenocarcinomas) in the nonampullary duodenum. Top panels: membranous staining of $\beta$-catenin. Bottom panels: nuclear staining of $\beta$-catenin. Arrowheads (yellow) indicate that nuclear $\beta$-catenin (green) is co-localized with ALDH1 (red). Bars: $50 \mu \mathrm{m}$. (b) Representative double-staining IHC of $\beta$-catenin (blue) and ALDH1 (brown) in a representative adenomatous lesion (adenoma) in the non-ampullary duodenum. Arrows indicate that nuclear $\beta$-catenin (blue) is co-localized with ALDH1 (brown). Bar: $50 \mu \mathrm{m}$. (B) (a) Showing percentages of ALDH1 only, nuclear $\beta$-catenin only, or double positive cells per all the tumor cells of 5 independent fields in non-ampullary duodenal adenoma and adenocarcinoma. Data shows means \pm SD. (b) the positivity of nuclear $\beta$-catenin-positive cells in total ALDH1-posive cells of adenomas and adenocarcinomas 
of gastric type adenoma in the proximal duodenum in nonampullary lesions.

We did not include any cases of ampullary duodenal adenomas or adenocarcinomas because ampullary neoplasms may have combined features of neoplasms of the small intestine including duodenum, distal bile duct, and/or pancreas. Adenocarcinomas are particularly rare in non-ampullary lesions compared with adenomas.

Nuclear $\beta$-catenin accumulation, a key effector of the Wnt signalling pathway, was frequent in adenoma rather than in adenocarcinoma. There were more ALDH1positive cells with CSC potential in adenocarcinomas compared to adenomas. Further, nuclear $\beta$-catenin in these cells was more frequently co-expressed in adenomas rather than in adenocarcinomas. Our data suggest that Wnt/ $\beta$ catenin activation might be associated with ALDH1expressing CSCs in a subset of non-ampullary duodenal adenomas, i.e. intestinal type adenomas. There are similar findings in breast cancer, where ALDH1-positive cells show higher levels of $\mathrm{Wnt} / \beta$-catenin signalling compared with ALDH1-negative cells [24]. By contrast, in adenocarcinomas of the proximal duodenum, Wnt $/ \beta$ catenin activation was less frequent and ALDH1-positive cells were more frequent than adenoma. This result may be caused by the development of diverse tumors in the proximal duodenum compared with the distal duodenum. Adenocarcinomas are difficult to categorize due to their heterogeneity, but adenomas are easily categorized into intestinal type, gastric foveolar type, and pyloric gland adenomas.

Our study showed nuclear $\beta$-catenin expression in $84 \%$ of adenomas and $33.3 \%$ of adenocarcinomas in nonampullary duodenal lesions. A previous study observed aberrant $\beta$-catenin expression and nuclear/cytoplasmic translocation in $38.1 \%$ of duodenal adenocarcinomas, including both non-ampulla and ampulla of Vater [37]. In contrast to our results in non-ampullary lesions, $8.2 \%$ of adenomas and $40.5 \%$ of adenocarcinomas showed nuclear $\beta$-catenin expression in ampulla (of Vater) lesions [38]. Alterations in $\beta$-catenin may occur late in neoplasm

\section{The pathogenesis of adenoma/carcinoma in the non-ampullary duodenum}

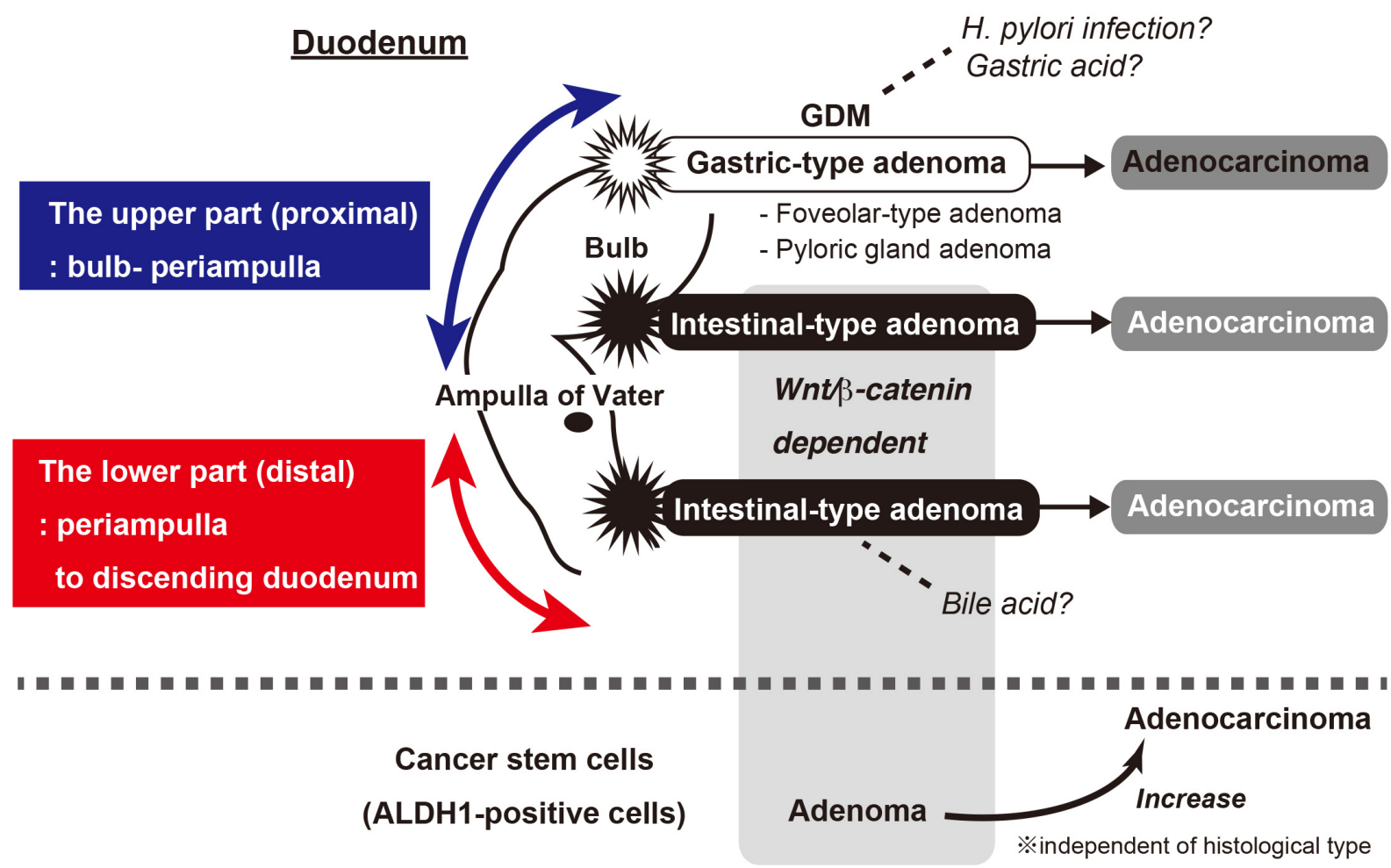

Figure 6: The visualization of sporadic adenoma and adenocarcinoma pathogenesis in the non-ampullary duodenum. In non-ampullary lesions of the duodenum, Wnt/ $\beta$-catenin pathway is associated with intestinal type adenoma in the proximal and distal duodenum, while the pathway was independent of gastric type adenoma in the proximal duodenum. The gastric type adenoma has two subtypes: gastric foveolar-type and pyloric gland adenoma. The gastric type adenoma is associated with GDM (gastric duodenal metaplasia), which may be injured from gastric acid or a Helicobacter pylori infection. In the intestinal type adenoma, Wnt/ $\beta$-catenin activation occurs as well as in the majority of colon carcinogenesis. The ALDH1-positive cells, a putative cancer stem cell marker, is more expressed in adenocarcinoma than adenoma. However, the co-localization with nuclear $\beta$-catenin in adenoma is more frequent than adenocarcinoma. 
carcinogenesis in the ampulla of Vater. However, our data suggests that in non-ampullary lesions, alterations in $\beta$-catenin might be an early event.

In contrast to the typical adenoma-carcinoma sequence in the majority of colorectal carcinogenesis, the development of adenocarcinoma in non-ampullary duodenal lesions seems to have two types; 1) de novo type, i.e. gastric type, that occurs independent of the $\mathrm{Wnt} / \beta$-catenin pathway, 2) adenoma-carcinoma sequence type, i.e. intestinal type, that develops dependent of the $\mathrm{Wnt} / \beta$-catenin pathway like colon carcinogenesis. A possible difference between the nonampullary duodenum and colorectum can be observed in the developing gut. Developmentally, the duodenum appears to share characteristics with the stomach, particularly the antrum, rather than the colorectum [39]. In our study, all the gastric-type adenomas with GDM developed in the proximal duodenum, and were associated with membranous $\beta$-catenin. This suggests that the non-ampullary proximal duodenum is likely to have gastric characteristics injured by the environment, such as gastric acid and H. pylori.

Regarding colorectal cancers, the CSC population detected using ALDH1 enzymatic activity is typically very small, including $0.01-1 \%$ of the population of cancer cells [40]. In contrast, immunohistochemical studies examining various types of cancers have reported remarkably high fractions of positive cells [41, 42]. Only one immunohistochemical study has examined small intestinal adenocarcinoma, and strong ALDH1 expression was observed in $33.3 \%$ of all cases [43]. In our study of nonampullary lesions, ALDH1-positive cells occurred more frequently in adenocarcinomas than in adenomas, and high ALDH1 expression (Score 3 and 4) was observed in 33\% (3/9) of adenocarcinoma cases. This is similar to a colon adenocarcinoma study where ALDH1 positivity in IHC experiments demonstrated an increasing number of colonic stem cells over colon cancer progression [23]. Thus, the ALDH1-based CSC marker can be used to track CSCs in the sporadic non-ampullary duodenal adenoma/adenocarcinoma during the tumorigenesis as well as colon tumorigenesis.

In conclusion, nuclear $\beta$-catenin accumulation is more correlated with adenomas rather than adenocarcinomas in the non-ampullary proximal duodenum. The co-localization of nuclear $\beta$-catenin and ALDH1 is common in adenoma, and ALDH1 is highly expressed in adenocarcinoma rather than in adenoma. The pathogenesis may differ in sporadic adenoma and adenocarcinoma of the non-ampullary duodenum, especially the proximal and distal duodenum.

\section{MATERIALS AND METHODS}

\section{Patient and tissue samples}

Tumor specimens were obtained from patients through biopsy, EMR, or ESD at Gifu University Hospital between 2008 and 2015, and Gifu Municipal Hospital between 2012 and 2015. Informed consent was obtained from all patients.

\section{Diagnosis of adenoma and adenocarcinoma}

Using hematoxylin and eosin-stained sections, adenoma was diagnosed when the tumor was circumscribed and found to be composed of tubular structures showing intraepithelial neoplasia. Adenocarcinoma was diagnosed when the tumor invaded into the lamina propria or through the muscularis mucosae. On biopsy, samples contained areas suggestive of true invasion. Adenocarcinoma without invasion was diagnosed when increased architectural distortion with glandular crowing and prominent cellular atypia and pleomorphic, hyperchromatic, pseudostratified nuclei were observed. The diagnoses were confirmed by at least two pathologists.

\section{Immunohistochemical staining}

All paraffin-embedded tissues were cut into $4 \mu \mathrm{m}$ thick serial sections and deparaffinized. These sections were stained with hematoxylin and eosin or used for IHC. For IHC, the sections were placed in citrate buffer ( $\mathrm{pH}$ 6.0), and then autoclaved at a chamber temperature of $121^{\circ} \mathrm{C}$ for $1 \mathrm{~min}$ to retrieve the antigen. The sections were then rinsed and blocked in 3\% hydrogen peroxide in methanol for $10 \mathrm{~min}$ to remove endogenous peroxidase. Non-specific binding sites were blocked in $0.01 \mathrm{M}$ phosphate-buffered saline ( $\mathrm{pH} 7.4$ ) containing $2 \%$ bovine serum albumin (Wako Pure Chemical, Osaka, Japan) for $40 \mathrm{~min}$. They were incubated with $\beta$-catenin antibody (Mouse IgG, 1:500; BD Transduction Laboratories, San Jose, CA, USA) and ALDH1A1 antibody (Rabbit IgG, 1:500; Abcam, Cambridge, UK) overnight at $4^{\circ} \mathrm{C}$.

Primary antibodies were detected using a biotinylated anti- mouse and rabbit IgG (1:300; Dako, Glostrup, Denmark) for $30 \mathrm{~min}$ at room temperature, followed by incubation with avidin-coupled peroxidase (Vectastain ABC kit; Vector Laboratories, Burlingame, CA, USA) for $30 \mathrm{~min}$. The bound complex was visualized using diaminobenzidine liquid chromogen (Sigma, St. Louis, MO, USA), and counterstained with hematoxylin. As a negative control, the primary antibody was replaced with normal serum IgG at a similar dilution.

For double-staining IHC, $\beta$-catenin and ALDH1 were used as primary antibodies. Signal amplification was performed using alkaline phosphatase-biotin complex (Vectastain), followed by a chromogenic reaction with an alkaline phosphatase substrate kit (Vecta Blue; Vector Laboratories) and diaminobenzidine.

For immunofluorescent (IF) staining, after treatment with primary antibodies, samples were incubated for $30 \mathrm{~min}$ at room temperature with FITC- or rhodamineconjugated secondary antibodies (1:500 dilution; Dako). 
DNA was labeled with 4', 6-diamidino-2-phenylindole. Histological evaluation was performed by two experienced pathologists (H.T. and A. N.), who were blinded to the clinical data.

\section{Assessment of $\beta$-catenin and ALDH1A1 immunostaining}

Staining of $\beta$-catenin was graded as either nuclear (moderate or strong staining of the nucleus) or membrane (very weak or negative in the nucleus). ALDH1 staining intensity scores were rated on a scale of $0-4$ according to the percentage of positive tumour cells $(0,<5 \%$ positive cells; 1, 5-10\%; 2, 11-30\%; 3, 31-50\%; 4, >50\%).

In double staining, percentages of nuclear $\beta$-catenin- and/or ALDH1-positive cells in adenoma and adenocarcinoma were obtained by manually counting positively stained cells in 10 representative fields of adenomatous or cancerous regions, in which nuclear $\beta$-catenin translocation was most frequently observed under $400 \times$ high-power magnification.

\section{Statistical analysis}

Statistical analysis and graphical presentation were performed using the GraphPad Prism 6.0 package (GraphPad, San Diego, CA, USA). The Mann-Whitney U, Fisher's exact test, or chi-square test was used to test the relationship between categorical variables as appropriate. $P<0.05$ was considered to indicate statistical significance.

\section{ACKNOWLEDGMENTS}

We would like to thank Kyoko Takahashi, Ayako Suga, Masayoshi Shimizu, and Reiko Kitazumi for their valuable technical assistance.

\section{CONFLICTS OF INTEREST}

The authors do not have any conflicts of interest.

\section{GRANT SUPPORT}

This study was supported by grants from the Ministry of Education, Culture, Sports, Science, and Technology of Japan; \#15K11289 (A.H.) and \#26430111 (H.T.).

\section{REFERENCES}

1. Lim $\mathrm{CH}$, Cho YS. Nonampullary duodenal adenoma: Current understanding of its diagnosis, pathogenesis, and clinical management. World J Gastroenterol. 2016; 22:853-861.
2. Culver EL, McIntyre AS. Sporadic duodenal polyps: classification, investigation, and management. Endoscopy. 2011; 43:144-155.

3. Johnson MD, Mackey R, Brown N, Church J, Burke C, Walsh RM. Outcome based on management for duodenal adenomas: sporadic versus familial disease. J Gastrointest Surg. 2010; 14:229-235.

4. Kaiser A, Jurowich C, Schonekas H, Gebhardt C, Wunsch $\mathrm{PH}$. The adenoma-carcinoma sequence applies to epithelial tumours of the papilla of Vater. Z Gastroenterol. 2002; 40:913-920.

5. Takashima M, Ueki T, Nagai E, Yao T, Yamaguchi K, Tanaka M, Tsuneyoshi M. Carcinoma of the ampulla of Vater associated with or without adenoma: a clinicopathologic analysis of 198 cases with reference to p53 and Ki-67 immunohistochemical expressions. Mod Pathol. 2000; 13:1300-1307.

6. Sellner F. Investigations on the significance of the adenomacarcinoma sequence in the small bowel. Cancer. 1990; 66:702-715.

7. Wikramanayake AH, Hong M, Lee PN, Pang K, Byrum CA, Bince JM, Xu R, Martindale MQ. An ancient role for nuclear beta-catenin in the evolution of axial polarity and germ layer segregation. Nature. 2003; 426:446-450.

8. Lee HK, Choi YS, Park YA, Jeong S. Modulation of oncogenic transcription and alternative splicing by betacatenin and an RNA aptamer in colon cancer cells. Cancer Res. 2006; 66:10560-10566.

9. Polakis P. The many ways of Wnt in cancer. Curr Opin Genet Dev. 2007; 17:45-51.

10. Wong SC, Lo ES, Chan AK, Lee KC, Hsiao WL. Nuclear beta catenin as a potential prognostic and diagnostic marker in patients with colorectal cancer from Hong Kong. Mol Pathol. 2003; 56:347-352.

11. Chiurillo MA. Role of the Wnt/beta-catenin pathway in gastric cancer: An in-depth literature review. World J Exp Med. 2015; 5:84-102.

12. Hsu HP, Shan YS, Jin YT, Lai MD, Lin PW. Loss of E-cadherin and beta-catenin is correlated with poor prognosis of ampullary neoplasms. J Surg Oncol. 2010; 101:356-362.

13. Yoshida A, Rzhetsky A, Hsu LC, Chang C. Human aldehyde dehydrogenase gene family. Eur J Biochem. 1998; 251:549-557.

14. Jackson B, Brocker C, Thompson DC, Black W, Vasiliou K, Nebert DW, Vasiliou V. Update on the aldehyde dehydrogenase gene (ALDH) superfamily. Hum Genomics. 2011; 5:283-303.

15. Christ O, Lucke $\mathrm{K}$, Imren $\mathrm{S}$, Leung $\mathrm{K}$, Hamilton $\mathrm{M}$, Eaves A, Smith C, Eaves C. Improved purification of hematopoietic stem cells based on their elevated aldehyde dehydrogenase activity. Haematologica. 2007; 92:1165-1172. 
16. Corti S, Locatelli F, Papadimitriou D, Donadoni C, Salani S, Del Bo R, Strazzer S, Bresolin N, Comi GP. Identification of a primitive brain-derived neural stem cell population based on aldehyde dehydrogenase activity. Stem Cells. 2006; 24:975-985.

17. Tomita H, Tanaka K, Tanaka T, Hara A. Aldehyde dehydrogenase 1A1 in stem cells and cancer. Oncotarget. 2016; 7:11018-32. doi: 10.18632/oncotarget.6920.

18. Taniguchi H, Moriya C, Igarashi H, Saitoh A, Yamamoto $\mathrm{H}$, Adachi Y, Imai K. Cancer stem cells in human gastrointestinal cancer. Cancer Sci. 2016; 107:1556-1562.

19. Katoh M. Network of WNT and other regulatory signaling cascades in pluripotent stem cells and cancer stem cells. Curr Pharm Biotechnol. 2011; 12:160-170.

20. Takahashi-Yanaga F, Kahn M. Targeting Wnt signaling: can we safely eradicate cancer stem cells? Clin Cancer Res. 2010; 16:3153-3162.

21. Wakamatsu Y, Sakamoto N, Oo HZ, Naito Y, Uraoka N, Anami K, Sentani K, Oue N, Yasui W. Expression of cancer stem cell markers ALDH1, CD44 and CD133 in primary tumor and lymph node metastasis of gastric cancer. Pathol Int. 2012; 62:112-119.

22. Deng S, Yang X, Lassus H, Liang S, Kaur S, Ye Q, Li C, Wang LP, Roby KF, Orsulic S, Connolly DC, Zhang Y, Montone K, et al. Distinct expression levels and patterns of stem cell marker, aldehyde dehydrogenase isoform 1 (ALDH1), in human epithelial cancers. PLoS One. 2010; 5:e10277.

23. Huang EH, Hynes MJ, Zhang $\mathrm{T}$, Ginestier C, Dontu G, Appelman H, Fields JZ, Wicha MS, Boman BM. Aldehyde dehydrogenase 1 is a marker for normal and malignant human colonic stem cells (SC) and tracks SC overpopulation during colon tumorigenesis. Cancer Res. 2009; 69:3382-3389.

24. Jang GB, Kim JY, Cho SD, Park KS, Jung JY, Lee HY, Hong IS, Nam JS. Blockade of Wnt/beta-catenin signaling suppresses breast cancer metastasis by inhibiting CSC-like phenotype. Sci Rep. 2015; 5:12465.

25. Shaoul R, Marcon MA, Okada Y, Cutz E, Forstner G. Gastric metaplasia: a frequently overlooked feature of duodenal biopsy specimens in untreated celiac disease. J Pediatr Gastroenterol Nutr. 2000; 30:397-403.

26. Kushima R, Borchard F, Hattori T. A new aspect of gastric metaplasia in Crohn's disease: bidirectional (foveolar and pyloric) differentiation in so-called 'pyloric metaplasia' in the ileum. Pathol Int. 1997; 47:416-419.

27. Harris AW, Gummett PA, Walker MM, Misiewicz JJ, Baron JH. Relation between gastric acid output, Helicobacter pylori, and gastric metaplasia in the duodenal bulb. Gut. 1996; 39:513-520.

28. Harris A, Misiewicz JJ. Treating Helicobacter pylori--the best is yet to come? Gut. 1996; 39:781-783.

29. Rubio CA, Nesi G, Zampi GC, de Ruiz PA, Jessurun J, Jonasson J, Hojman R, Kogan Z, Antonioli D, Miller
ML, Hirota T, Itabashi T, Mandai K, et al. Gastric ciliated metaplasia. A study of 3406 gastrectomy specimens from dwellers of the Atlantic and the Pacific basins. J Clin Pathol. 2005; 58:605-610.

30. Maruoka D, Arai M, Ishigami H, Okimoto K, Saito K, Minemura S, Matsumura T, Nakagawa T, Katsuno T, Yokosuka O. Sporadic nonampullary duodenal adenoma/ carcinoma is associated with not only colon adenoma/ carcinoma but also gastric cancer: association of location of duodenal lesions with comorbid diseases. Scand J Gastroenterol. 2015; 50:333-340.

31. Okada K, Fujisaki J, Kasuga A, Omae M, Kubota M, Hirasawa T, Ishiyama A, Inamori M, Chino A, Yamamoto Y, Tsuchida T, Nakajima A, Hoshino E, Igarashi M. Sporadic nonampullary duodenal adenoma in the natural history of duodenal cancer: a study of follow-up surveillance. Am J Gastroenterol. 2011; 106:357-364.

32. Wetmore C. Sonic hedgehog in normal and neoplastic proliferation: insight gained from human tumors and animal models. Curr Opin Genet Dev. 2003; 13:34-42.

33. Boon EM, van der Neut R, van de Wetering M, Clevers $H$, Pals ST. Wnt signaling regulates expression of the receptor tyrosine kinase met in colorectal cancer. Cancer Res. 2002; 62:5126-5128.

34. Walker MM, Dixon MF. Gastric metaplasia: its role in duodenal ulceration. Aliment Pharmacol Ther. 1996; 10:119-128.

35. Matsubara A, Sekine S, Kushima R, Ogawa R, Taniguchi H, Tsuda H, Kanai Y. Frequent GNAS and KRAS mutations in pyloric gland adenoma of the stomach and duodenum. $\mathrm{J}$ Pathol. 2013; 229:579-587.

36. Nakagawa M, Kitazawa R, Kondo T, Ninomiya K, Okita M, Haraguchi R, Kitazawa S. Duodenal gastric heterotopia, sporadic or fundic gland polyp-associated, frequently carries beta-catenin mutation. Virchows Arch. 2014; 465:253-256.

37. Lee HJ, Lee OJ, Jang KT, Bae YK, Chung JY, Eom DW, Kim JM, Yu E, Hong SM. Combined loss of E-cadherin and aberrant beta-catenin protein expression correlates with a poor prognosis for small intestinal adenocarcinomas. Am J Clin Pathol. 2013; 139:167-176.

38. Park S, Kim SW, Lee BL, Jung EJ, Kim WH. Expression of E-cadherin and beta-catenin in the adenomacarcinoma sequence of ampulla of Vater cancer. Hepatogastroenterology. 2006; 53:28-32.

39. Yuasa Y. Control of gut differentiation and intestinal-type gastric carcinogenesis. Nat Rev Cancer. 2003; 3:592-600.

40. Enderling H, Hlatky L, Hahnfeldt P. Cancer Stem Cells: A Minor Cancer Subpopulation that Redefines Global Cancer Features. Front Oncol. 2013; 3:76.

41. Kahlert C, Gaitzsch E, Steinert G, Mogler C, Herpel E, Hoffmeister M, Jansen L, Benner A, Brenner H, ChangClaude J, Rahbari N, Schmidt T, Klupp F, et al. Expression analysis of aldehyde dehydrogenase 1A1 (ALDH1A1) 
in colon and rectal cancer in association with prognosis and response to chemotherapy. Ann Surg Oncol. 2012; 19:4193-4201.

42. Lugli A, Iezzi G, Hostettler I, Muraro MG, Mele V, Tornillo L, Carafa V, Spagnoli G, Terracciano L, Zlobec I. Prognostic impact of the expression of putative cancer stem cell markers CD133, CD166, CD44s, EpCAM, and ALDH1 in colorectal cancer. Br J Cancer. 2010; 103:382-390.

43. Eom DW, Hong SM, Kim G, Bae YK, Jang KT, Yu E. Prognostic Significance of CD44v6, CD133, CD166, and ALDH1 Expression in Small Intestinal Adenocarcinoma. Appl Immunohistochem Mol Morphol. 2015; 23:682-688. 